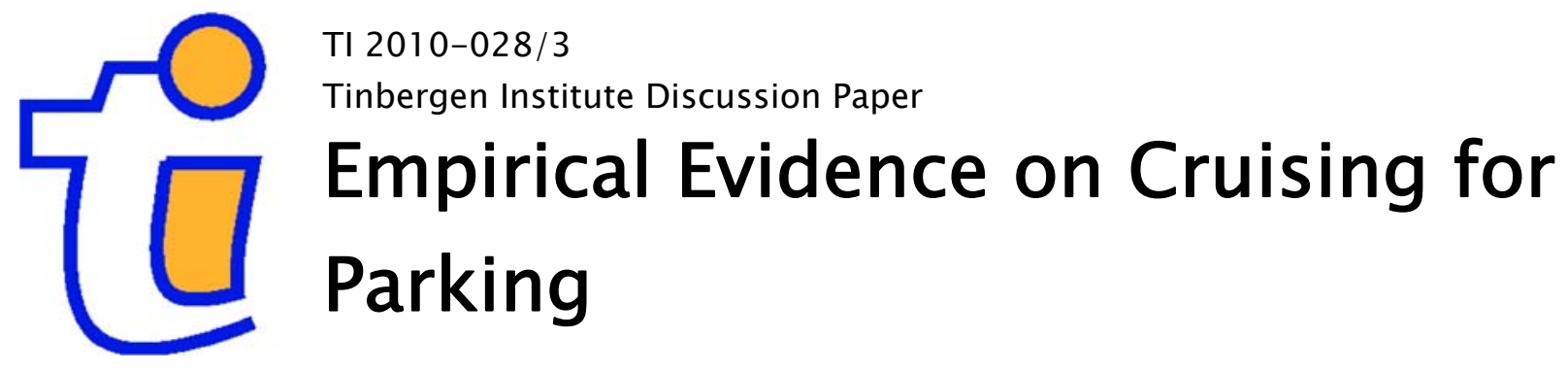

Jos van Ommeren*

Derk Wentink

Piet Rietveld*

VU University Amsterdam.

* Tinbergen Institute. 


\section{Tinbergen Institute}

The Tinbergen Institute is the institute for economic research of the Erasmus Universiteit Rotterdam, Universiteit van Amsterdam, and Vrije Universiteit Amsterdam.

Tinbergen Institute Amsterdam

Roetersstraat 31

1018 WB Amsterdam

The Netherlands

Tel.: +31(0)205513500

Fax: $+31(0) 205513555$

Tinbergen Institute Rotterdam

Burg. Oudlaan 50

3062 PA Rotterdam

The Netherlands

Tel.: + $31(0) 104088900$

Fax: $+31(0) 104089031$

Most TI discussion papers can be downloaded at http://www.tinbergen.nl. 


\title{
Empirical evidence on cruising for parking
}

\author{
Jos Van Ommeren \\ Derk Wentink \\ Piet Rietveld
}

$08 / 03 / 2010$

Abstract. The literature on car cruising is dominated by theory. This is the first article that examines cruising for parking using a nation-wide random sample of car trips. We exclude employer-provided and residential parking. We demonstrate that cruising time is, on average, 36 seconds per car trip. Car drivers appear to choose their cruising time in line with economic theory: cruising time increases with travel duration as well as with parking duration, but falls with income. We also find that cruising is more common with shopping and recreation than for work-related activities. Cruising has a distinctive pattern over the day with a peak in the morning, so the order of arrival is essential to parking.

VU University, FEWEB, De Boelelaan, 1081 HV Amsterdam, the Netherlands; Email: jommeren@,feweb.vu.nl. We would like to thank Netherlands Organisation for Scientific Research (NWO) for funding and Marcel Hoogzaad for valuable assistance. 


\section{Introduction}

There is a growing theoretical literature on cruising for parking (Glazer and Niskanen, 1992; Arnott and Rowse, 1999, 2009; Anderson and de Palma, 2004; Arnott and Inci, 2006). ${ }^{1}$ As far as we know, there is little corresponding empirical literature on cruising. For example, as emphasised by Arnott and Inci (2006) and Arnott and Rowse (2009), it is even unknown what proportion of cars are cruising for parking. In the current paper, we focus on cruising time, viz. the car driver's search time for a parking space. Shoup (2005) reports that, based on a sample of 22 studies, the average share of traffic cruising is 30 percent and the average cruising time just under 8 minutes in downtown areas. This information is difficult to generalise nation-wide, because these studies measure cruising in areas where it may have been expected.

One objective of the paper is to provide descriptive information about cruising using a nation-wide dataset that excludes employer-provided and residential parking. Using data from the Netherlands, we show that in $30 \%$ of car trips there is some cruising involved. The nationalaverage cruising time for parking is 36 seconds per car trip, which may be compared to an average travel time of 20 minutes. So, cruising time involves only a few percent of overall travel time. Nevertheless, its relevance in terms of time loss is comparable to the loss induced by congestion. $^{2}$

The main objective of the current paper is to examine whether cruising behaviour is rather random or can be explained by micro-economic theory. So, we aim to explain variation in

\footnotetext{
${ }^{1}$ In this literature, it is emphasised that cruising for parking is frequently a consequence of underpricing of on-street parking and is then socially wasteful. By increasing parking prices to the appropriate level, the number of vacant parking places increases, so cruising time will fall.

${ }^{2}$ Cruising time may be the result of lack of information about the exact location of parking. So, not all cruising time can be considered to be an external cost.
} 
cruising time as a function of demand characteristics (e.g. income, parking duration, travel duration) and supply characteristics (e.g. time of arrival, type of destination). Our main finding is that the effects of these characteristics on chosen cruising time is by and large in line with theory.

\section{Theoretical setting}

To understand the determinants of cruising behaviour, we discuss an extremely stylised partial equilibrium static model, which may be interpreted as a reduced form specification of structural models such as Calthrop (2001). The model is partial because cruising time at each parking facility is exogenously given, so we ignore the effect of cruising behaviour on cruising time per parking space. This model assumes that car drivers wait at congested parking facilities. One may imagine other behavioural strategies to search for a parking space (e.g. driving around while searching). The advantage of the current setup is that it allows us to derive testable propositions while keeping the mathematical arguments to a minimum. So, in this setup, when drivers have chosen a parking space, they do not search for another one, and they simply wait for a vacant parking space. Cruising time is essentially equivalent to waiting time.

We make the assumption that the car driver chooses between a continuum of parking spaces that are identical in all aspects (including the walking time to the final destination), except for the parking fee and the cruising time. The parking duration is exogenously determined. The driver has perfect information, so given the choice of a parking space, cruising time is known. Cruising time varies per parking space: the higher the parking fee for a parking space, the lower the cruising time (otherwise the sparking space will never be used, see e.g. Calthrop, 2001). The parking space, and therefore cruising time, is optimally chosen by car drivers. Given these assumptions, and given additional assumptions that state how certain characteristics affect the 
demand for and supply of cruising, it is rather straightforward to derive testable hypotheses of the effects of certain characteristics on cruising time, such as income, parking duration etc. For the formal model, see Appendix A. We will now discuss the variables that are related to the car drivers' demand for cruising.

First, high-income drivers cruise less, given the additional, but common, assumption that higher income travellers have a higher value of travel time. Second, a longer parking duration (at the destination) induces more cruising, because the savings per unit of cruising time are higher. Third, if the marginal benefit of car travel falls with travel duration, which seems a reasonable assumption, then cruising will increase with travel duration. Fourth, the number of passengers in a car reduce cruising time, as the marginal cost of cruising increases with the number of (adult) passengers (as the total time loss increases in the number of passengers). However, one may also argue that cruising is stressful, and if passengers reduce this stress (e.g. by providing directions) then cruising time may increase. This aspect is not captured by the model.

We will also discuss the effect of two types of variables that are related to the 'supply' of cruising. First, the supply of parking varies per type of destination, so the relationship between cruising time and the parking fee is destination specific. This results in longer cruising times at certain destinations. For destinations such as shopping and recreation, cruising time may be higher than for work destinations. Second, in dynamic models, cruising time may be zero at certain times (e.g. in the morning) and then increase during the day until a peak is reached and then falls back to zero (e.g. at night), see Calthrop, 2001. So, a dynamic model implies that the time order of arrival is relevant (see also, Arnott et al., 1991 in a spatial context). At most types of destinations (the main exception is residential parking), the demand for parking is zero early in the morning, then increases and then falls before the evening, implying that cruising will peak 
during the day. This aspect is also ignored in the model. Finally, we emphasise that this model is extremely stylised, because it does not capture dynamic aspects, ignores search over space, and is a partial-equilibrium model.

\section{Empirical analysis}

Our data are derived from the Dutch National Travel Survey (MON) for the years 2005, 2006 and 2007. In this survey, a (randomly-chosen) proportion of respondents, who have made (at least) one car trip (as driver or passenger) on a certain day, are asked to report their cruising time for a parking spot for one particular trip. The cruising time reported only includes in-vehicle search time for a parking space and excludes any other time losses due to searching (e.g. additional walking to the destination). The question about cruising is formulated as follows: "How much time have you searched for a parking spot?" The reported cruising time (in minutes) is a subjective estimate of cruising time, so our estimate likely contains measurement error. If the measurement error is random, which seems plausible, then this has no effect on the consistency of the reported estimates. Cruising time is reported for all parking destinations except employerprovided and residential parking. For the latter two destinations, search time is thought to be almost negligible, because residential areas usually have sufficient on-street supply (the main exception is downtown Amsterdam and centres of other old cities, see van Ommeren et al, 2009).

We are then left with 11,425 observations, of which 7,081 refer to on-street and 4,344 to off-street parking in a private or public parking lot. For our main results, we do not distinguish between on-street and off-street parking, as they have almost identical parking tariffs. In the Netherlands, the average on-street parking fee is $€ 1.55$, the average off-street parking fee is $€$ 1.52 (PDN, 2009). This contrasts with assumptions in the US cruising literature that relies on the 
notion that on-street parking tariffs are (too) low, so drivers park off-street, that is more expensive, to avoid cruising. In many other European countries, e.g. Belgium, off-street prices are also very close to on-street prices (see also, Calthrop, 2001).

In the survey, there is no information whether the car driver had to pay for parking. The descriptives of cruising time show that $30 \%$ of the car drivers cruise before finding a parking spot, but the large majority cruises for just one minute. Average cruising time is 36 seconds. $^{3}$ Cruising time seldomly exceeds 3 minutes (see Table 1).

Table 1. Distribution of cruising time

\begin{tabular}{ll}
\hline No cruising & 0.70 \\
1 minute & 0.24 \\
2 minutes & 0.04 \\
3 minutes & 0.01 \\
More than 3 minutes & 0.01 \\
\hline
\end{tabular}

In order to determine the effect of explanatory variables, we use area fixed effects linear regression models. ${ }^{4}$ Areas are defined by 4 digit postcodes. Area fixed effects essentially control for unobserved spatial variation in factors such as the supply of parking and the location-specific level of parking tariffs. ${ }^{5}$ In this case, we also control for a selection effect, as we use a sample of car drivers, and it is likely that the decision to travel by car depends on the expected cruising

\footnotetext{
${ }^{3}$ Average cruise time for on-street parking is 30 seconds; for off-street parking 50 seconds. These descriptives suggest that on-street parking is less attractive (e.g. more expensive) than off-street parking, but other explanations cannot be excluded. For example, it may be the case that search within off-street buildings is more time consuming.

${ }^{4}$ Tobit analyses generate similar qualitative results, but as these analyses rely on stronger assumptions to identify the marginal effects we are interested in, we prefer regression analyses (see Angrist and Pischke, 2009). Another issue is that Tobit analyses do not generate consistent estimates when the number of observations per fixed effect is small.
} 
time at the destination). In our analysis, we distinguish between 2,365 areas (The Netherlands has 16 million inhabitants, so, on average, an area contains about 6,700 inhabitants, roughly 3,300 residences).

In addition to the variables discussed in the introduction, we control for gender and age. Economic theory provides no clear idea about the effect of gender and age on cruising. We use a quadratic specification for age. We specify income in logs (in the survey, income is asked for in 6 broad categories; we take the mid-value of each category) and include additional dummies for respondents who do not report their income and for those who do not have any personal income. Furthermore, we include number of passengers, type of activity at destination (recreation, shopping, and 'other' (e.g. hospital visit)), where the reference category is work (commuting and business trips), the logarithm of duration of the car trip (excluding cruising), the logarithm of the parking duration as well as the arrival time at the destination. The potential endogeneity of the car trip and parking duration variables is ignored. Although cruising, travel and activity time are, at least theoretically, simultaneously determined, the exogeneity assumption is empirically reasonable because cruising time is only a few percent of average travel time and negligible compared to average parking time.

The specification of arrival time needs more attention. We have first estimated models where we included hourly dummies for travel between 6 a.m. and 22 a.m. These results suggest a non-linear relationship with a morning peak, but as all dummies are statistically insignificant, this interpretation may be spurious. Therefore, we show the results for a cubic specification ${ }^{6}$ of

\footnotetext{
${ }^{5}$ Note that the theoretical model incorporates the relationship between the cruising time and parking tariffs, but this relationship is likely location-specific.

${ }^{6}$ A quadratic specification imposes a maximum at noon, so this specification is too restrictive.
} 
arrival time $h$, so $f(h)=\alpha h+\beta h^{2}+\gamma h^{3}$, and, for time-consistency, impose that $f(0)=f(24){ }^{7}$ Given estimates of $\alpha, \beta$ and $\gamma$, we have calculated the peak cruising time (and its standard error using the delta method).

In the theoretical model, cruising and waiting are equivalent. In more elaborate spatial models where car drivers search over space for a vacant parking space, cruising may be closely related to walking time. So, we do not control for walking time (from the parking space to the travel destination, e.g. the shopping mall), because this variable is highly endogenous with respect to cruising time. For example, car drivers that (maybe unexpectedly) are not able to find a vacant parking space close to the travel destination will cruise for a parking space that is (almost always) further away from the destination. ${ }^{8}$

The means and standard deviations of the explanatory variables can be found in the last column of Table 2. They show that the sample is quite representative for car drivers. Furthermore, it appears that $69 \%$ of destinations refer to recreation or shopping, and $21 \%$ refer to work-related parking. The main results can be found in the first column of Table 2 . They show that income has a negative effect on cruising time, consistent with the notion that higher incomes have a higher value of travel time. This result suggests that a doubling of income reduces cruising time by 4 seconds (about $10 \%$ of the mean cruising time). Cruising times are substantially higher for recreation (about 10 seconds), and particularly shopping activities (18 seconds), than for working. Our preferred explanation is that this is a supply effect and that

\footnotetext{
${ }^{7}$ The latter restriction implies that $\alpha=-\beta 24-\gamma 576$, so $f(h)=\beta\left(h^{2}-24 h\right)+\gamma\left(h^{3}-576 h\right)$. So, we estimate $\beta$ and $\gamma$ and then calculate $\alpha$.

${ }^{8}$ We have examined the association between cruising time and walking time, by including walking time in the analysis, which is not reported here. We find a strong positive relationship between cruising and walking time. We emphasise that this relationship cannot be interpreted as a causal effect.
} 
parking is supplied near shopping centres below peak levels, which creates cruising at certain hours. We believe that this is the most plausible explanation. We cannot exclude other ('demand') explanations. For example, another explanation is that the costs of cruising depend on the drivers' cost relating to uncertainty of arriving on time, that are presumably higher for work-related activities. 
Table 2.

Analysis of cruising time

\begin{tabular}{|c|c|c|c|c|}
\hline & ( & (II) & (III) & (IV) \\
\hline & AREA FE & $\begin{array}{c}\text { MUNICIPALITY } \\
\text { FE }\end{array}$ & OLS & $\begin{array}{c}\text { Descriptives } \\
\text { Mean (sd) }\end{array}$ \\
\hline \multirow[t]{2}{*}{ Male } & 0.005 & -0.002 & -0.001 & 0.48 \\
\hline & $(0.021)$ & $(0.020)$ & $(0.020)$ & $(0.50)$ \\
\hline \multirow[t]{2}{*}{ Age } & 0.002 & 0.002 & 0.001 & 49 \\
\hline & $(0.004)$ & $(0.003)$ & $(0.003)$ & (16) \\
\hline \multirow[t]{2}{*}{ Age squared/100 } & -0.004 & -0.004 & -0.004 & 26 \\
\hline & $(0.004)$ & $(0.004)$ & $(0.004)$ & (16) \\
\hline \multirow[t]{2}{*}{ Income unknown } & 0.120 & 0.101 & 0.088 & 0.14 \\
\hline & $(0.030)$ & $(0.027)$ & $(0.031)$ & $(0.34)$ \\
\hline \multirow[t]{2}{*}{ No income } & 0.032 & 0.012 & 0.002 & 0.08 \\
\hline & $(0.036)$ & $(0.033)$ & $(0.034)$ & $(0.28)$ \\
\hline \multirow[t]{2}{*}{ Income (in log) } & -0.044 & -0.039 & -0.033 & 9.86 \\
\hline & $(0.022)$ & $(0.020)$ & $(0.019)$ & $(0.49)$ \\
\hline \multirow[t]{2}{*}{ Number of passengers } & 0.014 & 0.016 & 0.013 & 0.16 \\
\hline & $(0.011)$ & $(0.010)$ & $(0.010)$ & $(0.90)$ \\
\hline \multirow[t]{2}{*}{ Recreation destination } & 0.096 & 0.081 & 0.082 & 0.38 \\
\hline & $(0.029)$ & $(0.026)$ & $(0.025)$ & $(0.49)$ \\
\hline \multirow[t]{2}{*}{ Shopping destination } & 0.176 & 0.183 & 0.171 & 0.31 \\
\hline & $(0.031)$ & $(0.028)$ & $(0.026)$ & $(0.46)$ \\
\hline \multirow[t]{2}{*}{ Other destination } & 0.023 & 0.025 & 0.043 & 0.10 \\
\hline & $(0.045)$ & $(0.040)$ & $(0.031)$ & $(0.29)$ \\
\hline \multirow[t]{2}{*}{ Travel duration (in logminutes) } & 0.030 & 0.038 & 0.040 & 2.62 \\
\hline & $(0.011)$ & $(0.010)$ & $(0.011)$ & $(0.95)$ \\
\hline \multirow[t]{2}{*}{ Parking duration (in logminutes) } & 0.025 & 0.028 & 0.028 & 4.23 \\
\hline & $(0.008)$ & $(0.008)$ & $(0.007)$ & $(1.35)$ \\
\hline Arrival time & yes & yes & yes & \\
\hline Year dummies & yes & yes & yes & \\
\hline Municipality population (in log) & & & yes & \\
\hline Area fixed effects & yes & no & no & \\
\hline Municipality fixed effects & & yes & no & \\
\hline No. of fixed effects & 2,365 & 432 & 0 & \\
\hline Average group size & 4.8 & 26.0 & & \\
\hline Number of observations & 11,425 & 11,425 & 11,425 & \\
\hline \multirow[t]{2}{*}{ Peak cruising time (in hours and min.) } & 10.59 & 7.54 & 8.26 & \\
\hline & $(2.32)$ & $(1.58)$ & $(1.40)$ & \\
\hline
\end{tabular}

Notes: Robust std. errors in parentheses. Reference category of destination is work.

The estimates for arrival time imply that cruising peaks in the morning (to be exact, at 10.59 as reported at the bottom of Table 2) and is minimal around midnight. The difference 
between the maximum (peak) and minimum (the though) is 16 seconds with a standard error of 7 seconds. Hence, cruising time first increases over the day because parking spaces have been taken by earlier arrivals (and then falls later on). This is consistent with a range of parking models which demonstrate that the order of arrival is essential to parking (e.g. Arnott et al., 1991; Zhang et al., 2008). Furthermore, we find that both car travel duration and parking duration have a positive effect on cruising, in line with economic theory. A doubling of travel duration, as well as parking duration, increases cruising time by about 3 seconds. Finally, we don't find any effect for the number of passengers.

As a sensitivity analysis, we have re-estimated models without and with area fixed effects defined at the level of the municipality (see columns (2) and (3)). In essence, the results remain the same (implying that the observed explanatory variables are orthogonal to spatial structure). The main difference is that peak cruising time is now more precisely estimated, and the $95 \%$ confidence interval of peak is between 6 and $10 \mathrm{am}$. We have also re-estimated all models separately for off-street and on-street parking. For proper interpretation of these results, we emphasise that we don't know whether drivers who park off-street first have searched on-street (or the other way around). In principle, it is possible to estimate a simultaneous choice of onstreet and off-street parking, but this requires a much larger dataset. The results are similar to the results discussed above. However the results seem to imply that the marginal effects are higher for off-street parking, except for the effect of travel time. Other differences are likely caused by the reduction in sample size for each parking destination. Note that the sample size is too small to repeat the analysis for the centre of business district of large cities, where one may anticipate that the sizes of the effects are more pronounced. 


\section{Conclusion}

The literature on cruising is dominated by theory (Glazer and Niskanen, 1992; Arnott and Rowse, 1999, 2009; Anderson and de Palma, 2004; Arnott and Inci, 2006) with few empirical evidence on the determinants of cruising (Shoup, 2006). This is the first article that investigates cruising for parking using a nation-wide random sample of car trips (excluding residential and employer-provided parking). We find that in about $30 \%$ of the trips considered car drivers cruise for parking, and the average cruising time per trip is 36 seconds (about the same order of magnitude as the nation-wide loss in time due to congestion in the Netherlands). We find that car drivers choose their cruising time in line with a standard economic model. Cruising increases with car travel duration and with parking duration, but falls with income. We also find that cruising is more common with shopping and recreation than for work-related activities. Cruising has a distinctive pattern over the day with a peak in the morning so the order of arrival is essential to parking (as argued by Arnott et al., 1991).

\section{References}

Anderson, S.P. and A. de Palma (2004), The economics of pricing parking, Journal of Urban Economics, 55, 1-20

Angrist, J.D. and J.S. Pischke (2009), Mostly Harmless Econometrics, Princeton University

Arnott, R., A. de Palma and R. Lindsey (1991), A temporal and spatial equilibrium analysis of commuter parking, Journal of Public Economics, 45, 301-335

Arnott, R. (2006), Spatial competition between parking garages and downtown parking policy, Transport Policy, 13, 458-469

Arnott, R. and E. Inci (2006), An integrated model of downtown parking and traffic congestion, Journal of Urban Economics, 60, 418-442 
Arnott, R. and J. Rowse (1999), Modelling parking, Journal of Urban Economics, 45, 97-124.

Arnott, R. and J. Rowse (2009), Downtown parking in auto city, Regional Science and Urban Economics, 39, 1-14

Calthrop E., S. Proost and K. van Dender (2000), Parking policies and road pricing, Urban Studies, 37(1), 63-76

Calthrop, E. (2001), Essays in urban transport economics, $\mathrm{PhD}$ Thesis 151, Leuven

Calthrop, E. (2002), Evaluating on-street parking policy, Working Paper 2002-03, Leuven

Glazer, A. and E. Niskanen (1992), Parking fees and congestion, Regional Science and Urban Economics, 22, 123-132

Manning, A. (2003), The real thin theory: monopsony in modern labour markets, Labour Economics, 10, 105-131

Proost, S. and K. van Dender (2008), Optimal urban transport pricing in the presence of congestion, economies of density and costly public funds, Transportation Research Part $A, 42,1220-1230$.

Shoup, D.C. (2005), The High Cost of Free-parking, Planners Press, Chicago.

Shoup, D.C. (2006), Cruising for Parking, Transport Policy, 13, 479-486.

Van Ommeren, J.N., D. Wentink and J. Dekkers (2009), The real price of parking policy, Tinbergen Institute Discussion Paper, 2009-083/3, Amsterdam

Zhang, X., H.J. Huang and H.M. Zhang (2008), Integrated daily commuting patterns and optimal road tolls and parking fees in a linear city, Transportation Research B, 42, 38-56 


\section{Appendix A}

\section{A basic cruising model}

We suppose that car drivers choose between parking spaces that vary in their cruising time and parking fee. It is assumed that car drivers minimize the sum of the cruising and monetary parking costs: $n v\left(T_{t}\right) T_{c}+p\left(T_{c}, x\right) T_{p}$, where $n$ is the number of persons in the car, $v$ is the value of time (per person), which is a negative function of the travel time (excluding cruising) $T_{t}$, so $\partial v / \partial T_{t}<$ 0 , and a function of the variable $x$, which represents supply variables such as the type of destination (e.g. shopping). Furthermore, $T_{c}$ is the self-chosen cruising time and $T_{p}$ denotes the exogenous parking duration. Finally, $p\left(T_{c}, x\right)$ denotes the marginal costs of parking that depends on the cruising time $T_{c}$. It is assumed that $p^{\prime}<0$ and $p^{\prime \prime}>0$, where $p^{\prime}=\partial p / \partial T_{c}$. Given these assumptions each driver chooses a unique parking space. The first order condition is now that $n v+p^{\prime} T_{p}=0$. It is then straightforward to show that:

$d T_{c} / d n=-v\left(p^{\prime \prime} T_{p}\right)^{-1}<0 ; d T_{c} / d v=-n\left(p^{\prime \prime} T_{p}\right)^{-1}<0 ; d T_{c} / d T_{p}=-p^{\prime} / p^{\prime \prime}>0 ;$

$d T_{c} / d T_{t}=-n \partial v / \partial T_{t}\left(p^{\prime \prime} T_{p}\right)^{-1}>0$.

Furthermore, $\frac{d T_{c}}{d x}=-\frac{\partial^{2} p}{\partial T_{c} \partial x} / \frac{\partial^{2} p}{\partial T_{c} \partial T_{c}}$

so the sign of $\mathrm{dT}_{\mathrm{c}} / \mathrm{dx}$ depends on the sign of $\partial^{2} \mathrm{p} / \partial \mathrm{T}_{\mathrm{c}} \partial \mathrm{x}$. If it is negative (so the effect of $T_{c}$ on $p$ is stronger for higher $x$ ), then $d T_{c} / d x$ is positive. 


\begin{tabular}{|c|c|c|c|c|c|c|}
\hline & (I) & (II) & (III) & (IV) & (V) & $(\mathrm{VI})$ \\
\hline & On-street & On-street & On-street & Off-street & Off-street & Off-street \\
\hline & $\mathrm{FE}$ & $\mathrm{FE}$ & OLS & $\mathrm{FE}$ & $\mathrm{FE}$ & OLS \\
\hline \multirow[t]{2}{*}{ Male } & -0.033 & -0.018 & -0.014 & 0.104 & 0.033 & 0.031 \\
\hline & $(0.024)$ & $(0.022)$ & $(0.010)$ & $(0.046)$ & $(0.040)$ & $(0.040)$ \\
\hline \multirow[t]{2}{*}{ Age } & 0.000 & 0.005 & 0.005 & 0.003 & -0.001 & -0.005 \\
\hline & $(0.004)$ & $(0.004)$ & $(0.003)$ & $(0.008)$ & $(0.007)$ & $(0.007)$ \\
\hline \multirow[t]{2}{*}{ Age squared/100 } & -0.003 & -0.004 & -0.003 & -0.003 & 0.004 & 0.004 \\
\hline & $(0.003)$ & $(0.004)$ & $(0.004)$ & $(0.004)$ & $(0.005)$ & $(0.005)$ \\
\hline \multirow[t]{2}{*}{ Income unknown } & 0.095 & 0.065 & 0.052 & 0.260 & 0.166 & 0.166 \\
\hline & $(0.034)$ & $(0.029)$ & $(0.028)$ & $(0.068)$ & $(0.052)$ & (0.068) \\
\hline \multirow[t]{2}{*}{ No income } & -0.042 & -0.038 & -0.040 & 0.146 & 0.085 & 0.059 \\
\hline & $(0.040)$ & $(0.036)$ & (0.029) & $(0.076)$ & $(0.066)$ & (0.077) \\
\hline \multirow[t]{2}{*}{ Income (in log) } & -0.027 & -0.020 & -0.026 & -0.121 & -0.086 & -0.052 \\
\hline & $(0.025)$ & $(0.022)$ & $(0.022)$ & $(0.047)$ & $(0.040)$ & $(0.035)$ \\
\hline \multirow[t]{2}{*}{ Number of passengers } & 0.026 & 0.025 & 0.021 & 0.006 & 0.001 & -0.002 \\
\hline & $(0.012)$ & $(0.011)$ & $(0.012)$ & $(0.022)$ & $(0.020)$ & (0.019) \\
\hline \multirow[t]{2}{*}{ Recreation destination } & 0.091 & 0.067 & 0.071 & 0.147 & 0.122 & 0.100 \\
\hline & $(0.030)$ & $(0.026)$ & $(0.025)$ & $(0.074)$ & $(0.097)$ & $(0.056)$ \\
\hline \multirow[t]{2}{*}{ Shopping destination } & 0.065 & 0.082 & 0.067 & 0.272 & 0.237 & 0.221 \\
\hline & $(0.035)$ & $(0.031)$ & $(0.027)$ & $(0.076)$ & $(0.060)$ & $(0.052)$ \\
\hline \multirow[t]{2}{*}{ Other destination } & -0.040 & -0.008 & 0.003 & 0.145 & 0.120 & 0.156 \\
\hline & $(0.046)$ & $(0.041)$ & $(0.035)$ & $(0.120)$ & $(0.097)$ & $(0.069)$ \\
\hline \multirow[t]{2}{*}{ Travel duration (in logminutes) } & 0.039 & 0.036 & 0.032 & 0.001 & 0.022 & 0.046 \\
\hline & $(0.012)$ & $(0.011)$ & $(0.011)$ & $(0.026)$ & $(0.021)$ & $(0.026)$ \\
\hline \multirow[t]{2}{*}{ Parking duration (in logminutes) } & 0.011 & 0.020 & 0.017 & 0.058 & 0.048 & 0.053 \\
\hline & $(0.009)$ & $(0.008)$ & $(0.008)$ & $(0.020)$ & $(0.016)$ & $(0.012)$ \\
\hline Arrival time & yes & yes & yes & yes & yes & yes \\
\hline Year dummies & yes & yes & yes & yes & yes & yes \\
\hline Municipality population (in log) & & & yes & & & yes \\
\hline Area fixed effects & yes & no & no & yes & no & no \\
\hline Municipality fixed effects & yes & yes & no & yes & yes & no \\
\hline No. of fixed effects & 2,045 & 425 & 0 & 1,529 & 396 & 0 \\
\hline Average group size & 3.5 & 16.4 & & 2.8 & 10.8 & \\
\hline Number of observations & 7,081 & 7,081 & 7,081 & 4,344 & 4,344 & 4,344 \\
\hline \multirow[t]{2}{*}{ Peak cruising time (in hours) } & 14.120 & 7.956 & 9.528 & 12.938 & 10.108 & 9.845 \\
\hline & $(1.659)$ & (3.271) & (3.016) & (3.703) & $(3.246)$ & (3.150) \\
\hline
\end{tabular}

Notes: Robust std. errors in parentheses. Reference category of destination is work. 
